\title{
Coronavirus: Why Men are More Vulnerable to Covid-19 Than Women?
}

\author{
George M. Bwire ${ }^{1}$ (D) \\ Accepted: 28 May 2020 / Published online: 4 June 2020 \\ (C) Springer Nature Switzerland AG 2020
}

\begin{abstract}
Amid of coronavirus disease 2019 (Covid-19) pandemic, much emphasis was initially placed on the elderly or those who have preexisting health conditions such as obesity, hypertension, and diabetes as being at high risk of contracting and/or dying of Covid-19. But it is now becoming clear that being male is also a factor. The epidemiological findings reported across different parts of the world indicated higher morbidity and mortality in males than females. While it is still too early to determine why the gender gap is emerging, this article point to several possible factors such as higher expression of angiotensin-converting enzyme2 (ACE 2; receptors for coronavirus) in male than female, sex-based immunological differences driven by sex hormone and $\mathrm{X}$ chromosome. Furthermore, a large part of this difference in number of deaths is caused by gender behavior (lifestyle), i.e., higher levels of smoking and drinking among men compared to women. Lastly, studies reported that women had more responsible attitude toward the Covid-19 pandemic than men. Irresponsible attitude among men reversibly affect their undertaking of preventive measures such as frequent handwashing, wearing of face mask, and stay at home orders.
\end{abstract}

Keywords Covid-19 · Morbidity $\cdot$ Mortality $\cdot$ Epidemiology

\section{Introduction}

The world is in the midst of the coronavirus disease 2019 (Covid-19) pandemic, an outbreak which was first reported in December 2019, Wuhan city, the capital of Hubei province in China [1]. By Jan 7, 2020, Chinese scientists had isolated, severe acute respiratory syndrome coronavirus 2 (SARSCoV-2), initially known as a novel coronavirus 2019 (2019$\mathrm{nCoV}$ ), from these patients with virus-infected pneumonia [2], which was later designated coronavirus disease 2019 (Covid19) in February 2020, by World Health Organization (WHO).

Covid-19 adds to the list of zoonotic coronavirus disease after SARS and the Middle East respiratory syndrome (MERS) [2]. SARS-CoV, MERS-CoV, and SARS-CoV-2 all belong to the $\beta$-coronavirus cluster [3], although

This article is part of the Topical Collection on Covid-19

George M. Bwire

georgebwire@gmail.com

1 Department of Pharmaceutical Microbiology, Muhimbili University of Health and Allied Sciences, P.O. Box 65001,

Dar es Salaam, Tanzania information on the sources of SARS-CoV-2 are limited but the current data showed that the SARS-CoV-2 was a combination of virus between a bat coronavirus and a coronavirus of unknown origin [4]. After comparing with coronavirus from other animals, it was established that snakes are the most likely wildlife source for the SARS-CoV-2 [4]. Additionally, a study by Benvenuto et al. [5] revealed that the SARS-CoV-2 was closely related to the coronavirus isolated from Chinese chrysanthemum-headed bats in 2015, supporting the possibility of bats to human transmission.

A multicenter cross-sectional study in China found that $80 \%$ of patients who contracted SARS-CoV-2 exhibited mild or moderate symptoms common to other viral respiratory infections [6]. On the other hand, SARS-CoV-2 has also demonstrated an ability to cause severe disease among certain groups, including older populations and individuals with underlying health conditions such as obesity, cardiovascular disease, and diabetes $[1,7]$. Nevertheless, a clear picture of the epidemiology of this Covid-19 is not yet well understood, but it is now becoming clear that being male is also a factor $[1,8$, 9]. While it is still too early to determine why the gender gap is emerging, this article point to several possible factors such as genetics, immunology, and behavioral as the associated factors. 


\section{Genetics}

The expression and distribution of the receptor influence the route of virus infection which has a major implication for understanding the pathogenesis and dictate the therapeutic strategies [10]. Angiotensin-converting enzyme-2 (ACE 2) encoded by ACE 2 gene has been proved to be the receptor for both the SARS-coronavirus (SARS-CoV) and the human respiratory coronavirus NL63 [11]. The current evidence on the receptors for SARS-CoV-2 suggest that ACE 2 are the responsible receptors for SARS-CoV-2. A study by $\mathrm{Lu}$ and colleagues documented that there was a similarity in receptorbinding properties between SARS-CoV-2 and SARS-CoV [12]. Another in vitro study demonstrated the positive correlation of ACE2 expression and the infection of SARS-CoV [13]. This means that an organism whose expression of ACE 2 protein is high has a facilitated environment for pathogenesis of coronavirus. Now, having this positive correlation between ACE 2 and coronavirus, different studies quantified the expression of ACE 2 proteins in human cells based on gender ethnicity, for example, in studying the expression level and pattern of human ACE 2 using a single-cell RNA-sequencing (RNA-seq), analysis indicated that Asian males had higher expression of ACE 2 than female [14]. Additionally, there was an evidence of differences in expression of ACE 2 between different ethnicity [11]. On the other hand, in establishing the expression of ACE 2 in the primary affected organ, a study conducted in Chinese population found that expression of ACE 2 in human lungs was extremely expressed in Asian male than female [10].

\section{Immunology}

To generate an appropriately controlled response during infections, immunological checkpoints, such as the inhibitory CD200 receptor (CD200R), greatly play a great role in balancing the immune system during microbial infection by stimulating and controlling hyperimmune mediated response [15]. CD200R is found in myeloid receptor [16] and expressed on macrophages, granulocytes, and dendritic cells (DCs), and it also expressed on other immune cells components such as T cells, B cells, and natural killer cells (NK cells) [17]. A study by Karnam and colleagues [17] reveled that CD200-CD200R and sex are host factors that together determine the outcome of viral infection. In the study conducted in mice, lack of CD200R signaling strongly enhanced type I interferon (IFN) production and viral clearance and improved the outcome of mouse hepatitis coronavirus infection, particularly in female mice. This means that organisms with high CD200R signaling have an enhance clearance of viral infection. A review which looked on association between sex difference in immune responses concluded that sex-based immunological differences contribute to variations in the susceptibility to infectious diseases and responses to vaccines in males and females. For example, sex-based differences in human leucocytes antigen (HLA) alleles and genes that encode for interleukin (IL), IL-4, IL-10, and the IL-12 receptor, have each been associated with differential antibody responses to vaccines against measles, mumps, hepatitis $\mathrm{A}$, tetanus, and diphtheria in children and adults where hormonal mechanisms are hypothesized to cause this effect [18]. Another review documented that women, especially during their reproductive years, are at increased risk of developing autoimmune diseases but are more resistant to infections than men. This is possibly mediated by several factors including sex hormones [19]. The concept of sex-based immunological differences driven by sex hormone and $\mathrm{X}$ chromosome has been well described by Elgendy et al., [20] where blocking estrogen receptors increased the mortality due SARS-CoV infection among female mice, suggesting the role played by estrogen receptors in blocking some viral infection.

\section{Behavior}

Since the first report of Covid-19 case in Wuhan, China, many clinical and epidemiological studies are coming out. Previously, much emphasis was initially placed on the elderly or those who have preexisting health conditions such as obesity, hypertension, and diabetes as being at risk of dying from the virus, but we are seeing with every country that provides us with sex-disaggregated data that men are more likely to die from the virus [21].

In the two hardest hit European nations, majority of the Covid-19 deaths in Italy [8] were male, while in Spain, almost twice as many men as women have died (http:// globalhealth5050.org/covid19/. Accessed April 19, 2020). Data from China first revealed a gender gap in deaths, where $41.9 \%$ of the admitted patients were female with majority of male sufferers dying compared to women [1]. Figures from the USA [7], South Korea [9], Germany, and UK who died (http://globalhealth5050.org/covid19/. Accessed April 19, 2020) have confirmed the pattern.

It is of no doubts, a part of this is biology (genetics and immunology), but a large part of this difference is also driven by gender behavior (life style), such as far higher levels of smoking and drinking among men compared to women [9]. Further, the recent study conducted in Spain (one of the hardest hit countries in Europe) reported that women had more responsible attitude toward the Covid-19 pandemic than men [22]. This may reversibly affect their undertaking of preventive measures such as frequent hand washing, face masking, and stay at home orders. 


\section{Conclusion}

The biological differences in the immune systems between men and women exist which may impact our ability to fight an infection including SARS-2-CoV-2. Generally, females are more resistant to infections than men, and this is possibly mediated by several factors including sex hormones and high expression of coronavirus receptors (ACE 2) in men but also life style, such as higher levels of smoking and drinking among men as compared to women. Additionally, women have more responsible attitude toward the Covid-19 pandemic than men. This may reversibly affect the undertaking of preventive measures such as frequent hand washing, wearing of face mask, and stay at home orders.

Acknowledgments The author would like to thank the editor(s) for accepting and commenting on the manuscript.

\section{Compliance with Ethical Standards}

Conflict of Interest The author declares that he has no conflict of interests.

\section{References}

1. Guan W, Ni Z, Hu Y, Liang W, Ou C, He J, et al. Clinical characteristics of coronavirus disease 2019 in China. N Engl J Med 2020;1-13.

2. Zhu N, Zhang D, Wang W, Li X, Yang B, Song J, et al. A novel coronavirus from patients with pneumonia in China, 2019. N Engl J Med. 2020;382(8):727-33.

3. Chen Y, Liu Q, Guo D. Emerging coronaviruses: genome structure, replication, and pathogenesis. J Med Virol. 2020;92(4):418-23.

4. Sun P, Lu X, Xu C, Sun W, Pan B. Understanding of COVID-19 based on current evidence. J Med Virol. 2020;10-3.

5. Benvenuto D, Giovanetti M, Ciccozzi A, Spoto S, Angeletti S, Ciccozzi M. The 2019-new coronavirus epidemic: evidence for virus evolution. J Med Virol. 2020;92(4):455-9.

6. Wu J, Liu J, Zhao X, Liu C, Wang W, Wang D, Xu W, Zhang C, Yu J, Jiang B, Cao H, Li L. Clinical characteristics of imported cases of coronavirus disease 2019 (COVID-19) in Jiangsu Province: a multicenter descriptive study. Clin Infect Dis. 2020.

7. Faure E, Kipnis E, Bortolotti P, Salik J. Clinical characteristics of Covid-19 in New York City. N Engl J Med. 2020;29(1):2016-7.

8. Onder G, Rezza G, Brusaferro S. Case-fatality rate and characteristics of patients dying in relation to COVID-19 in Italy. JAMA. 2020;2019:2019-20.
9. Shim E, Tariq A, Choi W, Lee Y, Chowell G. Transmission potential and severity of COVID-19 in South Korea. Int J Infect Dis [internet]. 2020;93:339-44. https://doi.org/10.1016/j.ijid.2020.03. 031.

10. Zhao Y, Zhao Z, Wang Y, Zhou Y, Ma Y, Zuo W. Single-cell RNA expression profiling of ACE2, the putative receptor of Wuhan 2019-nCov. BioRxiv [internet]. 2020;2020.01.26.919985. https:// doi.org/10.1101/2020.01.26.919985v1.

11. Cao Y, Li L, Feng Z, Wan S, Huang P, Sun X, et al. Comparative genetic analysis of the novel coronavirus (2019-nCoV/SARS-CoV2) receptor ACE2 in different populations. Cell Discov [internet]. 2020;6(1):4-7. https://doi.org/10.1038/s41421-020-0147-1.

12. Lu R, Zhao X, Li J, Niu P, Yang B, Wu H, et al. Genomic characterisation and epidemiology of 2019 novel coronavirus: implications for virus origins and receptor binding. Lancet [internet]. 2020;395(10224):565-74. https://doi.org/10.1016/S01406736(20)30251-8.

13. Li W, Sui J, Huang IC, Kuhn JH, Radoshitzky SR, Marasco WA, et al. The $\mathrm{S}$ proteins of human coronavirus NL63 and severe acute respiratory syndrome coronavirus bind overlapping regions of ACE2. Virology. 2007;367(2):367-74.

14. Zhao Y, Zhao Z, Wang Y, Zhou Y, Ma Y, Zuo W. Single-cell RNA expression profiling of ACE2, the receptor of SARS-CoV-2. BioRxiv Prepr. 2020. https://doi.org/10.1101/20200126919985. ;

15. Wright GJ, Cherwinski H, Foster-Cuevas M, Brooke G, Puklavec MJ, Bigler M, et al. Characterization of the CD200 receptor family in mice and humans and their interactions with CD200. J Immunol. 2003;171(6):3034-46.

16. Mihrshahi R, Barclay AN, Brown MH. Essential roles for Dok2 and RasGAP in CD200 receptor-mediated regulation of human myeloid cells. J Immunol. 2009;183(8):4879-86.

17. Karnam G, Rygiel TP, Raaben M, Grinwis GCM, Coenjaerts FE, Ressing ME, et al. CD200 receptor controls sex-specific TLR7 responses to viral infection. PLoS Pathog. 2012;8(5):1-8.

18. Klein SL, Flanagan KL. Sex differences in immune responses. Nat Rev Immunol. 2016;16(10):626-38.

19. Ghazeeri G, Abdullah L, Abbas O. Immunological differences in women compared with men: overview and contributing factors. Am J Reprod Immunol. 2011;66(3):163-9.

20. Elgendy IY, Pepine CJ. Jo ur of. Int J Cardiol [Internet]. 2020. https://doi.org/10.1016/j.ijcard.2020.05.026

21. Jordan RE, Adab P, Cheng KK. Covid-19: risk factors for severe disease and death. BMJ [Internet]. 2020;368(March):m1198. https://doi.org/10.1136/bmj.m1198.

22. De La Vega R, Barquín RR, Boros S, Szabo A. Could attitudes toward COVID-19 in Spain render men more vulnerable than women? Prepr. 2020. https://doi.org/10.31234/osf.io/dyxqn

Publisher's Note Springer Nature remains neutral with regard to jurisdictional claims in published maps and institutional affiliations. 